\title{
Validation of pyrazinamide in human plasma using Hplc-Uv for therapeutic drug monitoring \\ By Dyah Aryani Perwitasari
}




\section{AIP $\mid$ Conferenne Proceedings}

Validation of pyrazinamide in human plasma using Hplc-Uv for therapeutic drug monitoring

E. Mulyani, E. Darmawan, D. A. Perwitasari, U. A. Mulyani, and J. Atthobari

\section{0}

Citation: AIP Conference Proceedings 1746, 020031 (2016); doi: 10.1063/1.4953956

View online: http://dx.doi.org/10.1063/1.4953956

View Table of Contents: http://scitation.aip.org/content/aip/proceeding/aipcp/1746?ver=pdfcov

Published by the AIP Publishing

Articles you may be interested in

11

Validation of isoniazid for therapeutic drug monitoring in human plasma by high-performance liquid chromatography

AlP Conf. Proc. 1746, 020030 (2016); 10.1063/1.4953955

5

Prediction of UV spectra and UV-radiation damage in actual plasma etching processes using on-wafer monitoring technique

J. Appl. Phys. 107, 043302 (2010); 10.1063/1.3313924

Sonoporation of cell using therapeutic ultrasound for drug and gene delivery

J.Acoust. Soc. Am. 115, 2586 (2004); 10.1121/1.4784361

19

Production, HPLC separation and UV-vis spectroscopy of Li@C 70

AIP Conf. Proc. 442, 368 (1998); 10.1063/1.56517

Magnetite used to monitor functioning of human lung

Phys. Today 26, 20 (1973); 10.1063/1.3128228 


\title{
Validation of P11razinamide in Human Plasma Using Hplc- Uv for Therapeutic Drug Monitoring
}

\author{
E. Mulyani ${ }^{1, a)}$, E. Darmawan ${ }^{1,6)}$, D.A. Perwitasari ${ }^{1, \mathrm{c})}$, U.A. Mulyani2 ${ }^{2, \mathrm{~d})}, \mathrm{J}$. \\ Atthobari ${ }^{3, e)}$

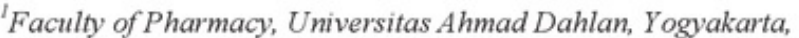 \\ ${ }^{2}$ Basic Technology Center for Biomedical and Health Research and Development Board of Health, Jakarta \\ ${ }^{3}$ Faculty of Medicine, Universitas Gadjah Mada, Yogyakarta \\ b) Corresponding author: diahperwitasari2003@yahoo.com \\ a) elly.mulyani17@yahoo.co.i \\ c) enddarmawan@googlemail.com \\ d) ullyadhie@gmail.com \\ e)j.atthobari@gmail.com
}

\begin{abstract}
Currently, Indonesia is in the $5^{\text {th }}$ rank of the highest tuberculosis prevalence over the world. The treatment of tuberculosis is going complicated due to the side effect experienced by the patients. The four combination of antituberculosis agent used in minimally 6 months of treatment could stimulate the hepatotoxicity as the one of the dominant side effect in tuberculosis treatment. Thus, it is important to do the Therapeutic Drug Monitoring (TDM) to optimize the duberculosis treatment. This study is aimed to validate the TDM of pyrazinamide in human plasma using High Perform 2 ce Liquid Chromatography-UV. We recruited 6 TB patients in the validation of pyrazinamide study. The C18 column shim- pack VP-ODS $(250 \mathrm{~mm} \times 4.6 \mathrm{~mm}$, id $5 \mu \mathrm{m})$ and aquabidest-acetonitrile as mobile phase were applied in this study. We used-Shimadzu HPLC system with a model AT LC20 LC 10AT pump, detector SPD 20A and LC solution software. 20 rformed the analysis for linearity, system appropriateness, accuracy and recovery to develop the validation method. This study has been approved by National Ethics Committee of Health Research. Our study shows that the linearity is good with value of $\mathrm{r}^{2}>0.99$ and the equation $\mathrm{y}=16740.876 \mathrm{x}-2953.615$. The CV TR and CV peak area for system suitability are $1.46 \%$ and $0.29 \%$, respectively. The LoD and LoQ value are 2.532 and $7.672 \mu \mathrm{g} / \mathrm{mL}$, respectively. The accuracy on the concentration of $1.00,8.00,60.00 \mathrm{ug} / \mathrm{ml}$ are $108.80 \%, 92.57 \%$ and $100.98 \%$, respectively for intraday accuracy and $103.18 \%, 92.44 \%$, and $94.94 \%$, respectively for interday accuracy. Furthermore, the precision on the concentration of $1.00,8.00,60.00 \mathrm{ug} / \mathrm{ml}$ are $1.17 \%, 3.57 \%, 3.32 \%$, respectively for intraday precision and $3.66 \%, 1.37 \%$ and $1.59 \%$, respectively for interday precision. In conclusion, the method which we applied in this study was sensitive and reliable for routine TDM of pyrazinamide.
\end{abstract}

Keyword: HPLC, Validation, Pyrazinamide, Tuberculosis

\section{BACKGROUND}

Tuberculosis is still being one of communicable diseases which can cause of death. In 2013, around 9.0 million people were still experiencing tuberculosis and 1.5 million people died due to it. The rapid diagnosis and effective treatment could decrease the mortality and prevalence of tuberculosis [1]. In developed country, even though the government has adopted the Direct Observed Treatment Shortcourses (DOTS) from WHO, the burden of tuberculosis is still high [1]. 
Isoniazid, Rifampicin, Ethambutol and Pyrazinamide are four anti-tuberculosis agents which should be used as first line treatment of tuberculosis for minimally 6 month duration of treatment. These combination may cause drug interaction and adverse drug reaction.

Pirazinamide is derivative of nicotinic acid which has similar structure with isoniazid. It well absorbed orally and widely distributed throught the body. Its mechanism as anti-tuberculosis is bactericidal and sterilizers working in acid medium, like machrophages and sites of acute inflammation. Pyrazinamidase is an enzyme which converts pyrazinamide into pyrazinoic acid. Pyrazinoic acid can decrease the intracellular $\mathrm{pH}$ which finally inactivated some enzymes [2,3]

Previous study about pharmacokinetic parameters of first-line antituberculosis showed that the treatment failure was depend on the pharmacokinetic parameters. The decrease of AUC of pyrazinamide, isoniazid and rifampicin may cause the poor long-term outcome [4]. Long duration of tuberculosis treatment may cause side effect. The most side effect experience by patients and were responsible on the poor adherence of tuberculosis treatment were hepatitis, dyspepsia, exanthema and athralgia. The major side effects of pyrazinamide are exanthema, hepatotoxicity and gastrointestinal disturbances. Thus, to increase patients' adherence during the tuberculosis treatment, the side effect monitoring should be closely done. Furthermore, patients should be well informed about these side effect and the medication to overcome the side effect.However, due to the complex treatment of tuberculosis, such as the potential of drug interaction and averse drug effect, the Therapeutic Drug Monitoring (TDM) can be done as one method to optimize the therapeutic effect and to minimize the adverse effect [5]. TDM also can be applied to define the slow response of patients and the resistance to the antituberculosis drugs. Thus, it is important to develop the TDM method in the country with high burden of tuberculosis disease. This study is aimed to validate the TDM of pyrazinamide in human plasma using HPLC-UV.

\section{METHOD}

\section{Subjects}

We recruited six adult tuberculosis patients of Public HealthCenter in Yogyakarta. The blood sample was drown from cubiti venous as much as $5 \mathrm{~mL} 2$ hours after the patients taking the antituberculosis drug. We gave the informed consent to the patients and asked them to signature the informed consent form as the participants. This research has been aproved by National Ethic Commitee of Health Research.

\section{Reagents}

This research used HP2 Shimadzu LC20 AT with LC 10AT pump, SPD 20A detector and LC solution software. The column C18 shim-pack VP-ODS $(250 \mathrm{~mm} \mathrm{x} 4.6 \mathrm{~mm}$, id $5 \mu \mathrm{m})$ was used in this instruments with other glass instruments (IWAKI pyrex).

The chemiclas used were from Merck (Germany), such as; methanol pro analysis (pa, 3906609839), diethyl ether (pa), $10 \%$ of trichlor acetic acid (TCA), acetonitryl (pa, 1632730213) and aquabidest. The pyrazinamide as standar compund was from BP/USP/COS.DIFC CO., LTD, Korea.

\section{Sample Preparation}

The standard curve was defined using $450 \mu \mathrm{L}$ of plasma added by $50 \mu \mathrm{L}$ pyrazinamide solution with concentration of $10.0 ; 80.0$ and $600.0 \mu \mathrm{g} / \mathrm{mL}$. The concentration of standard curve for linearity were $1.0 ; 2.0 ; 4.0$; $8.0 ; 16.0 ; 30.0$; and $60.0 \mu \mathrm{g} / \mathrm{mL}$. The concentration of standard curve for accuracy, intraday precision and interday precision were $1.0 ; 8.0$ and $60.0 \mu \mathrm{g} / \mathrm{mL}$. The $1000 \mu \mathrm{L}$ of TCA $10 \%$ was added into the solution then followed the next procedures; 20 minutes of vortex with maximal speed, 10 minutes of centrifuge with $13000 \mathrm{rpm}$ and $4^{\circ} \mathrm{C}$ of temperature. The $3 \mathrm{~mL}$ of ether was added into the supernatan for extraction process. This technique was aimed to separate pyrazinamide from other medications. The $20 \mathrm{~mL}$ of water solution of extraction process was injected into HPLC $[6,7]$ 


\section{System Suitability Test.}

The system suitability was defined by injected the $20 \mu \mathrm{L}$ of one point of standard curve into HPLC system. This procedures were replicated for 6 times and the coefficient of variance was defined from retention time and wide of area ratio $[8,9]$.

\section{Linearity.}

The Area Under the Curve (AUC) of pyrazinamide was assesed to get the linear regression equation; $y=b x+a$ with $\mathrm{R}>0.99$. The AUC showed the association between ration of pyrazinamide concentration and area wide or the high of peak of chromatography $[8,9]$.

\section{Limit of Detection (LoD) and Limit of Quantification (LoQ).}

The value of $\mathrm{LoD}$ and LoQ were define using the linear regression equation and Standard of Deviation (SD). The ration of signal to noise (S/N) with comparison of $3 ; 1$ was defined as $\mathrm{LoD}$ and the 10:1 comparison of $\mathrm{S} / \mathrm{N}$ was defined as LoQ [8,9].

\section{Accuracy}

The accuracy was examined from recovery. The value of recovery $(\%)$ was computed from actual concentration of pyrazinamide divided by theoritical concentration of pyrazinamide and was counted in $\%$. The criterion met accuracy with acceptance criteria required by USFDA was $80-120 \%[8,9]$.

\section{Intraday and Interday precision}

The precision intraday could be seen from coefficient of variation $(\mathrm{CV}, \%)$ of each replication of standard curve. The required $\mathrm{CV}$ for precision is less than $15 \%[8,9]$.

\section{Instrumental parameters}

$\begin{array}{ll}\text { HPLC } & \text { 2 } \\ \text { Stationary phase } & : \text { Shim-pack VP-ODS (C18) } 250 \\ & \times 4,6 \mathrm{~mm} \text { Column } \\ \text { Mobile phase } & : \text { Aquabidest : Acetonitrile } \\ & (97: 3) \% \\ \text { Flow rate } & : 1 \mathrm{~mL} / \text { minute } \\ \text { Detector } & : \text { UV } 262 \mathrm{~nm} \\ \text { Retention time } & : 15 \text { minute } \\ \text { Injected volume } & : 20 \mu \mathrm{L}\end{array}$

\section{RESULTS}

Our study defined that the method used in the validation procedures of pyrazinamide can be applied in clinical setting. Table 1 shows the results of system suitability test, linearity, LoD and LoQ. All the parameters met the requirement for validation test. 
TABLE 1. System suitability test, Linearity, LoD and LoQ of Pyrazinamide using HPLC

\begin{tabular}{ccc}
\hline Parameter & Required Criteria $^{\star}$ & Results \\
\hline System Suitability & $\mathrm{CV} \leq 2 \%$ & $\mathrm{CV} \mathrm{T}_{\mathrm{R}}=1,46 \%$ \\
& & $\mathrm{CV}$ peak area $=0,28 \%$ \\
Linearity & $\mathrm{r} \geq 0,99$ & $\mathrm{r}=0,999$ \\
LoD & $\mathrm{S} / \mathrm{N} \approx 3: 1$ & $\mathrm{y}=16740.876 \mathrm{x}-2953.615$ \\
LoQ & $\mathrm{S} / \mathrm{N} \approx 10: 1$ & $2,532 \mu \mathrm{g} / \mathrm{mL}$ \\
\hline
\end{tabular}

$\mathrm{CV}=$ Coefficient of Variation, $\mathrm{T}_{\mathrm{R}}=$ Retention Time, $\mathrm{r}=$ coefficient of correlation; $\mathrm{LOD}=$ Limit of Detection, $\mathrm{LOQ}$

=Limit of Quantification

* Adopted from [8]; [9]

The graph 1 presents the regression analysis results in system suitability test. System suitability was performed to determine the effectivity of system when the method was applied. The results of system suitability were met the required criteria which was less than $2 \%$. The linearity was shown in graph 1 with the $\mathrm{R}=0.999$ and the equation was $y=16740,876 x+2953.615$.

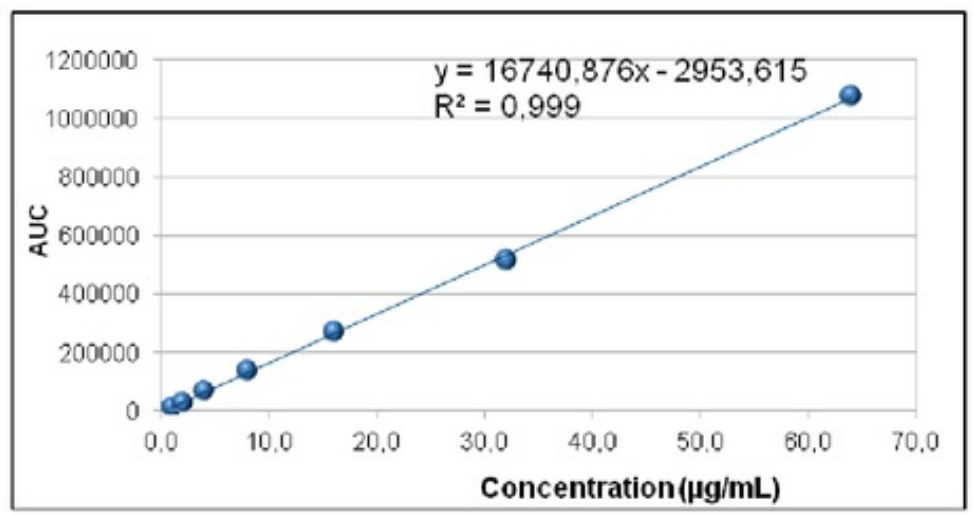

GRAPH 1. Linier regression between pyrazinamide concentration and AUC

The value of LoD and LoQ were established to understand the lowest concentration of sample which had good accurac 9 nd precision. Both of the LoD and LoQ had the value less than $3: 1$ and $10: 1$, respectively.

The precision and accuracy results are liste in Table 2 . The intraay and interday accuracy and precision were met the required criterion which are $\mathrm{CV}<15 \%$ and value between $80-120 \%$, respectively. Table 2 shows the precision and accuracy of TDM method of pyrazinamide in HPLC. 
TABLE 2. Precision and Accuracy of Pyrazinamide TDM using HPLC

\begin{tabular}{|c|c|c|c|c|c|c|c|}
\hline \multirow[b]{2}{*}{$\begin{array}{c}\text { Concentration } \\
(\mu \mathrm{g} / \mathrm{mL})\end{array}$} & \multicolumn{3}{|c|}{ Intraday $(n=6)$} & \multicolumn{3}{|c|}{ Interday $(n=6)$} & \multirow[b]{2}{*}{ Required Criteria * } \\
\hline & $\begin{array}{l}9 \\
\text { Mean } \pm \text { SD } \\
(\mu \mathrm{g} / \mathrm{mL})\end{array}$ & $\begin{array}{l}\text { Precision } \\
\text { (CV \%) }\end{array}$ & $\begin{array}{c}\text { Accuracy } \\
\text { (R \%) }\end{array}$ & $\begin{array}{c}\text { Mean } \pm \text { SD } \\
(\mu \mathrm{g} / \mathrm{mL})\end{array}$ & $\begin{array}{l}\text { Precision } \\
\text { (CV \%) }\end{array}$ & $\begin{array}{c}\text { Accuracy } \\
\text { (R \%) }\end{array}$ & \\
\hline 1 & $1,09 \pm 0,01$ & $1,17 \%$ & $108,80 \%$ & $1,03 \pm 0,04$ & $3,66 \%$ & $103,18 \%$ & Precision : \\
\hline 8 & $7,41 \pm 0,26$ & $3,57 \%$ & $92,57 \%$ & $7,39 \pm 0,10$ & $1,37 \%$ & $92,44 \%$ & $\mathrm{CV} \leq 15 \%$ \\
\hline 60 & $60,59 \pm 2,01$ & $3,32 \%$ & $100,98 \%$ & $56,96 \pm 0,91$ & $1,59 \%$ & $94,94 \%$ & $\begin{array}{c}\text { Accuracy : } \\
80-120 \%\end{array}$ \\
\hline
\end{tabular}

*: US FDA acceptance criteria for accuracy and precision

\section{DISCUSSION}

In general, we present that the method for pyrazinamide TDM using HPLC is valid and reliable. All the assay met the criteria involved in FDA and ICH. It means that this method can be applied in daily practice to understand the pharmacokinetic parameters of pyrazinamide which mostly related to the poor outcome of tuberculosis treatment. Previous study in tuberculosis patients with HIV infection showed that pyrazinamide peak concentration was low due to HIV infection [10]. Of the previous studies about TDM validation of antituberculosis, the HPLC-UV was the most valid and reliable instrument to do the TDM

One method which was used for pyrazinamide TDM was HPLC-diode array detector (HPLC-DAD) in two studies. The two studies showed that the method used in validation of rifampicin, isoniazide, ethambutol and pyrazinamide TDM in one pharmaceutical formulation met the requirement of linearity, precision and accuracy [11,12]. One of the method used mobile of monobasic sodium phosphate buffer with triethylamine and acetonitrile [12]. This method which is used in these previous studies was recommended due to its simplicity and accuracy [11].

The other method for pyrazinamide validation was in the formulation of ethionamide and pyrazinamide [13]. This study used reversed phase ion pair of HPLC for simultaneous detection of pyrazinamide and ethionamide and the mobile phase was trifluoroacetic acid in distilled water and acetonitrile:methanol. The concentration range of ethionamide and pyrazinamide was $0.1-3.0 \mu \mathrm{g} / \mathrm{mL}$ and met the requirements for linearity, Accuracy, precision and specifity [13]. The difference of mobile phase component to our study is due to the lipophilic and hydrophilic character of the antituberculosis. Our study only tests pyrazinamid which is more hydrophilic than ethionamide, thus we only need to us acetonitrile:aquabidest as the mobile phase. This technique is selective for pyrazinamide, because there is no overlapping retention time with other medications.

The previous study about TDM of antituberculosis is using electro spray tandem mass-spectrometry [14]. However, this method is quiet expensive to be applied in clinical setting in Indonesia. Due to the limitation of sophisticated instruments in our country, the method using HPLC/UV is the most possible method which could be applied in the clinical settings. To understand the pharmacokinetic parameter of antituberculosis drugs during the treatment is important due to the high prevalence of tuberculosis and the incidence of multi-drug resistance and HIV infection in Indonesia.

\section{CONCLUSION}

We conclude that the method to do TDM of pyrazinamide using HPLC is valid and can be used in clinical setting. 


\section{REFERENCES}

[1] World Health Organization Report, 2014, Global Tuberculosis Report, available online at 4.p://apps.who.int/iris/bitstream/10665/137094/1/9789241564809_eng.pdf (2014).

[2] H.M. Blumberg, W.J. Burman, R.E. Chaisson, C.L. Daley, S.C. Etkind, L.N. Friedman, Am. J. Respir. Crit. 18 . Med., 167, 603-62, (2003)

[3] Y. Zhang, W.W. Yew, Int. 21 uberc. Lung Dis., 13, 1320-1330 (2009).

[4] I Reynolds, S.K. Heysell, Expert Opin. Drug Metab. Toxicol., 10 813-823 (2014).

[5] 12 V. Yew, Clin. Chim. Acta, 313 31-36 (2001).

[6] 14 Glass, S.A.Kustrin, Y.J. Chen, and M.H. Wisch, J Chromatogr: Sci., 45, 38-44 (2007)

[7] Z. Zhou, X. Wu1 Q. Wei, Y. Liu, P. Liu, A. Ma, F. Zou, Anal. Bioanal. Chem., 405, 6323-6335 (2013).

[8] Anonymous., "International Conference on Harmonization (ICH) of Technical Requirements for Registration of Pharmaceuticals for Human, Validation of analytical procedures: Text and methodology Q2(R1)," available at http://www.ich_org/fileadmin/Public_Web_Site/ICH_Products/Guidelines/Quality/Q2_R1/Step4/Q2_R1_Guid eline.pdf $(2007$

[9] Anonymous, US Department of Health and Human Services FDA., "Guidance for Industry Bioanalytical Method 6 Validation," available at http:/www.fda.gov/downloads/Drugs/Guidance/ucm070107.pdf (2001).Awofeso N., "Anti-Tuberculosis Medication Side-Effects Constitute Major Factor for Poor Adherence to Tuberculosi 16 fatment," Bull World Heal 16 rgan. 86 , B-D (2008).

[10] 3 Chideya, C.A. Winston, C.A. Peloquin, Clin. Infect. Dis., 48, 1685-94 (2009).

[11] E Calleri, E. De Lorenzi, S. Furlanetto, G. Massolini, G. Caccialanza, J. Pharm. Biomed. Anal., 29, $1089-96$ 13 2)

[12] P.R. Chellini, E.B. Lages, P.H. Franco, F.H. Nogueira, I.C. César, G.A. Pianetti, J. AOAC Int., 98, 1234-9 (2015).

[13] C. J. Bhanushali, A.S. Zidan, Z. Rahman, M.J. Habib, AAPS Pharm. Sci. Tech., 14, 1313-20 (2013),

[14] J-W. Wu, H-H. Shih, S-C. Wang, T-H. Tsai, Anal. Chim Acta., 522, 231-9 (2004). 


\section{Validation of pyrazinamide in human plasma using Hplc-Uv for therapeutic drug monitoring}

ORIGINALITY REPORT

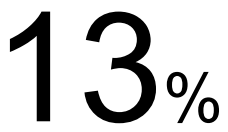

SIMILARITY INDEX

PRIMARY SOURCES

1 www.ipharmsciencia.com

Internet

41 words $-1 \%$

2 repositorio.ufla.br

Internet

29 words $-1 \%$

3 www.ijper.org

Internet

25 words $-1 \%$

4 Anderson. "Cycloserine", Antibacterial Agents Chemistry Mode of Action Mechanisms of Resistance

24 words $-1 \%$ and Clinical Applications, 05/29/2012

Crossref

5 Baklanov, Mikhail R., Jean-Francois de Marneffe, Denis Shamiryan, Adam M. Urbanowicz, Hualiang Shi,

24 words $-1 \%$ Tatyana V. Rakhimova, Huai Huang, and Paul S. Ho. "Plasma processing of low-k dielectrics", Journal of Applied Physics, 2013.

Crossref

6 aac.asm.org

Internet

23 words $-1 \%$

7 www.islandscholar.ca

Internet

22 words $-1 \%$

8 Zhang, HaiYang, John Ehiri, Huan Yang, Shenglan

Tang, and Ying Li. "Impact of Community-Based DOT

21 words $-1 \%$ on Tuberculosis Treatment Outcomes: A Systematic Review and Meta-Analysis", PLoS ONE, 2016. 
9 Wang, Yang, Rong Fan, Jiekun Luo, Tao Tang, Zhihua 20 words - 1\% Xing, Zian Xia, Weijun Peng, Wenzhu Wang, Huiying Lv, Wei Huang, Yizeng Liang, Lunzhao Yi, Hongmei Lu, and Xi Huang. "An Ultra high Performance Liquid Chromatography with tandem mass spectrometry method for plasma and cerebrospinal fluid pharmacokinetics of rhein in patients with traumatic brain injury after administration of rhubarb decoction", Journal of Separation Science, 2015. Crossref

10 www.nims.go.jp Internet

20 words $-1 \%$

11 McLawhon, Ronald. "Chromatographic Methods for Analysis of Antibiotics", Advances in Chromatographic 19 words $-1 \%$ Techniques for Therapeutic Drug Monitoring, 2009. crossref

12 Fang, P.F.. "Simultaneous determination of isoniazid, rifampicin, levofloxacin in mouse tissues and plasma 15 words $-1 \%$ by high performance liquid chromatography-tandem mass spectrometry", Journal of Chromatography B, 20100815 crossref

13 www.pba2013.org Internet

$$
14 \text { words }-<1 \%
$$

14 Wang, Libin, Yue Xu, Li Liang, Chunyan Diao, Xueying Liu, Jianchun Zhang, and Shengyong

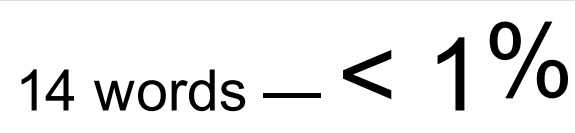
Zhang. "LC-MS/MS method for the simultaneous determination of PA-824, moxifloxacin and pyrazinamide in rat plasma and its application to pharmacokinetic study", Journal of Pharmaceutical and Biomedical Analysis, 2014.

Crossref

15 scitation.aip.org Internet

13 words $-<1 \%$

16 A. Requena-Mendez. "Rifampicin pharmacokinetics in Peruvian tuberculosis patients 12 words $-<1 \%$ with and without co-morbid diabetes or HIV", Antimicrobial 
Agents and Chemotherapy, 02/13/2012 Crossref

17 medicaljournals.se Internet

11 words $-<1 \%$

18 www.iegm.ru

10 words $-<1 \%$

19 www.ucsc.edu

Internet

10 words $-<1 \%$

20 eprints.ugd.edu.mk Internet

9 words $-<1 \%$

21 www.ajtmh.org

8 words $-<1 \%$

22 journals.plos.org

8 words $-<1 \%$ 